\title{
PREFERENTIAL DISCHARGE OF POLLUTANTS DURING SNOWMELT IN SCOTLAND
}

\author{
By E. M. MORRIS and A. G. THOMAS \\ (Institute of Hydrology, Natural Environment Research Council, Wallingford OX10 8BB, England)
}

ABSTRACT. At the beginning of spring snowmelt in an upland stream in Scotland a three-fold increase in total dissolved load occurs. This is shown to be the most significant of the acute events occurring during the year.

RÉSUMÉ. Débits préférentiels de polluants pendant la fonte des neiges en Écosse. Au commencement de la fonte des neiges au priniemps dans un cours d'eau de montagne en Écosse, on constate un triplement de la

\section{INTRODUCTION}

Work in Scandinavia has shown that at the onset of spring snowmelt there can be a marked deterioration in the water quality of snow-fed streams (Skartveit and Gjessing, 1979; Johannessen and others, 1980) caused by the preferential discharge of pollutants stored in the snow-pack. This increase is associated with an increase in acidity which is known to have a serious effect on aquatic organisms; the spring snowmelt occurs at a time which is critical for the hatching state of salmonid fish species (Johannessen and Henriksen, 1978). The level of acid precipitation in Scotland is comparable to that in Scandinavia (Fowler and others, 1982) so that there will be a similar amount of pollution in the snow-pack. Since snow is an important part of the hydrological cycle in the upland parts of Britair, a significant decrease in stream water quality cculd take place during snowmelt in this country. However, as we explain below, the different hydrological and meteorological conditions in Britain mean that it is impossible to predict $a$ priori that this will occur. Hitherto there has been no direct evidence of a deterioration in water quality during snowmelt in Britain although fish kills at the time of snowmelt have been recorded in south Scotland (personal communication from R.L. Newland). This paper describes a three-fold increase in total dissolved load at the beginning of spring snowmelt in an upland stream in Scotland and shows that it is by far the most significant of the acute events occurring during the year.

When snow melts the first melt water appearing at the bottom of the snow column contains much of the dissolved load of pollutants of the snow. This is because the impurities are concentrated on the surface of the ice grains and in the liquid water held between them and may thus be easily leached from the snow by the first melt water which percolates through. The effect of this preferential discharge of impurities on the water quality of the catchment stream may be discussed in terms of a simple mixing model. Let $f$ be the flow of water released from a snow-pack of average concentration $c_{\text {av }}$. The concentration $c$ of the melt water will vary from a maximum value of $c_{\max }>c_{a v}$ at the onset of melt to values much less than $c$ in the last stages. A component $f_{1}$ of the flow $f$ travels rapidly over the underlying surface and through pipes and macropores to charge totale en éléments dissous. On montre que c'est le plus significatif des principaux événements survenant dans le cours d'eau au cours de l'année.

ZUSAMMENFASSUNG. Bevorzugter Ausstoss von Schmutzstoffen während der Schneeschmelze in Schottland. Bei Beginn der Frühjahrsschneeschmelze steigt in einem Fluss des schottischen Hochlandes die Gesamtlast an mitgeführten Lösungsstoffen auf das dreifache. Es zeigt sich, dass dies das befeutendste unter den akuten Ereignissen im Lauf des Jahres ist.

the stream and may be assumed to have the same concentration, $c$, as the melt water. A second component $f_{2}$ travels more slowly through the soil and mixes with the soil water before reaching the stream. When $f_{1}$ reaches the stream the discharge will rise from the base flow value $f_{3}$ and the concentration will change from the base-flow concentration $c_{3}$ to $\left(f_{1} c+f_{3} c_{3}\right) /\left(f_{1}+f_{3}\right)$. To simplify the discussion, suppose that $f_{1}, f_{3}$, and $c_{3}$ are constant in time. Then the maximum concentration in the stream will be $c_{\text {peak }}=\left(f_{1} c_{\max }+f_{3} c_{3}\right) /\left(f_{1}+f_{3}\right)$ and the relative magnitude of the concentration peak produced by the snowmelt will be

$$
n=\frac{c_{\text {peak }}}{c_{3}}=1+\left[\left[\frac{c_{\text {max }}}{c_{3}}-1\right] /\left[1+\frac{f_{3}}{f_{1}}\right]\right] .
$$

Clearly there will only be a marked peak with say $n \geqslant 3$ if both $c_{\max } / c_{3}$ and $f_{1} / f_{3}$ are sufficiently large.

The magnitude of the base flow depends on the thickness and hydraulic conductivity of the organic and inorganic soils in the catchment and on the amount of water stored in them. Thus thin soils, impervious rock, and long periods of no rain or snowmelt lead to low values of $f_{3}$. The magnitude of $f_{1}$ depends on the snowmelt rate and on the condition of the soil, which controls the partition of $f$ into "fast" and "slow" snowmelt components.

The concentration of the base flow depends on the average concentration of the precipitation $\bar{c}$, the residence time of water in the soil, and the geochemical reactions occurring there. For a given input, a thin organic soil on slowly-weathering impervious rock will produce the lowest values of base-flow concentration $c_{3}$

$\bar{c}$. The value of $c_{\max }$ will always be several times that of $c_{a v}$ at the onset of melt because of preferential elution. However, $c_{\mathrm{av}}$ will decrease from $c_{\mathrm{av}}=\bar{c}$ before the first melt episode of the season to values much less than this after the snow has been leached by several melting episodes. Hence $c_{\max }$ will also decrease from $c_{\max }>\bar{c}$ to $c_{\max }<\bar{c}$.

It is not surprising that peaks of pollution have been observed at the onset of the annual snowmelt flood in some Scandinavian streams. In these high mountain catchments the bulk of the snow accumulates during the winter at sub-zero temperatures and is melted during a short period in the spring. There is a large snowmelt 
flood $\left(f_{1} \gg f_{3}\right)$ and, since this is the first snowmelt episode $c_{\max }>\bar{c}_{3}$. The soils are thin, on a granite bedrock, so $c_{3} \approx \bar{c}$. Thus $c_{\max }>c_{3}$ and the two conditions for a marked pollution peak hold. However, the pattern of snowmelt is different in Britain; it is usual for there to be several episodes of melting in a single winter, even in the highest areas. Snowmelt floods do occur but not every year and not necessarily during the first melt episode of the season. Therefore the pollutants may be released in several small, unimportant events with, say, $n \approx 1$, rather than in one major surge as in the Scandinavian case.

\section{RESULTS AND DISCUSSION}

As part of an investigation of the acute effects of acid rain in British conditions, electrical conductivity, stage, and stream temperature were measured at a gauging point $998 \mathrm{~m}$ above sea-level in Ciste Mhearad, a corrie on the southeast side of Cairngorm Mountain. The catchment defined by this gauging point has an area of $0.4 \mathrm{~km}^{2}$ and a median height of $1131 \mathrm{~m}$. The soil consists of a thin organic mat overlying fairly coarse-grained pink granite composed of quartz and red feldspar with a little mica. The vegetation is sparse and typical of mountain tundra. The data were recorded at $20 \mathrm{~min}$ intervals using an Institute of Hydrology solid-state logger throughout the period 19 October 1982 to 17 August 1983. The stage measurements were converted to discharge using a calibration curve established by dilution gauging. The absolute error in discharge is c. $5 \times 10^{-3} \mathrm{~m}^{3} \mathrm{~s}^{-1}$. The conductivity data were corrected to $25^{\circ} \mathrm{C}$ using the stream temperature measurements and are precise to $\pm 5 \%$. An empirical relation between electrical conductivity at $25^{\circ} \mathrm{C}$ and total dissolved solid was established for the stream. The relation is linear and gives total dissolved solid values precise to $\pm 10 \%$.

Figure 1 shows discharge and conductivity corrected to $25^{\circ} \mathrm{C}$ as a function of time during the first major snowmelt event of the year. Noise is present in the discharge record because the stage was measured in mid-stream, not in a stilling well. The average value of conductivity before the melt is $21 \mu \mathrm{S} \mathrm{cm}{ }^{-1}$. The peak in conductivity comes very quickly after the onset of melt with a maximum value of $63 \mu \mathrm{S} \mathrm{cm}^{-1}$. The ratio of these two values, the maximum concentration factor, is $n=3.0$. The second and third peaks in discharge are both larger than the first peak but produce far smaller peaks in conductivity. This is clear evidence of preferential discharge of pollutants at the onset of melt. The measurements of the pollutant levels in the snow before and after the melt support this.

At the onset of melt the average water-equivalent of the snow-pack was $22.5 \mathrm{~cm}$, which is equivalent to an average snow depth over the catchment of $45 \mathrm{~cm}$ using an average snow density of $500 \mathrm{~kg} \mathrm{~m}^{-3}$. Samples of snow taken before the melt had an average total dissolved load of $20 \mathrm{~g} \mathrm{~m}^{-3}$, which is the same as the average total dissolved load of fresh snow samples. Thus the pollutant load in the snow per unit area before melt was $c .4 .6 \mathrm{~g} \mathrm{~m}^{-2}$. After the first melt episode, which lasted two days, $4.3 \%$ of the snow had melted but $7.8 \%$ of the load had been discharged to the stream. By the end of the third episode, after $24 \mathrm{~d}, 80 \%$ of the snow had melted and $86 \%$ of the load had been removed. Samples of snow taken at this time had a total dissolved load of $12 \mathrm{~g} \mathrm{~m}^{-3}$, equivalent to an average pollutant load of c. $0.6 \mathrm{~g} \mathrm{~m}^{-2}$ for the average snow depth of $9 \mathrm{~cm}$. The maximum concentration factor $n=3.0$ for the stream water is higher than the maximum value of 2 found by Johannessen and others (1977) for stream water in two catchments of similar area $\left(0.98 \mathrm{~km}^{2}\right.$ and $\left.0.56 \mathrm{~km}^{2}\right)$ in Norway. However, since their water samples were taken daily this may be an under-estimate of the true maximum. Since $f_{3} / f_{1}=0.2$ at the time of the concentration peak (Fig. 1), Equation (1) gives an estimate of $c_{\max } / c_{3} \approx 3.4$. Since $c_{3}>\varepsilon_{\mathrm{av}}$ the maximum concentration factor for the melt water $c_{\max } / c_{\mathrm{ay}}$ is certainly greater than 3.4 . The range of values of $c_{\max } / c_{\mathrm{av}}$ found for melt water in field and laboratory experiments is 3-7 (Johannessen and others, 1977; Johannessen and Henriksen, 1978; Colbeck, 1981). Since Equation (1) does not take any account of dispersion processes within the catchment it is likely that the melt
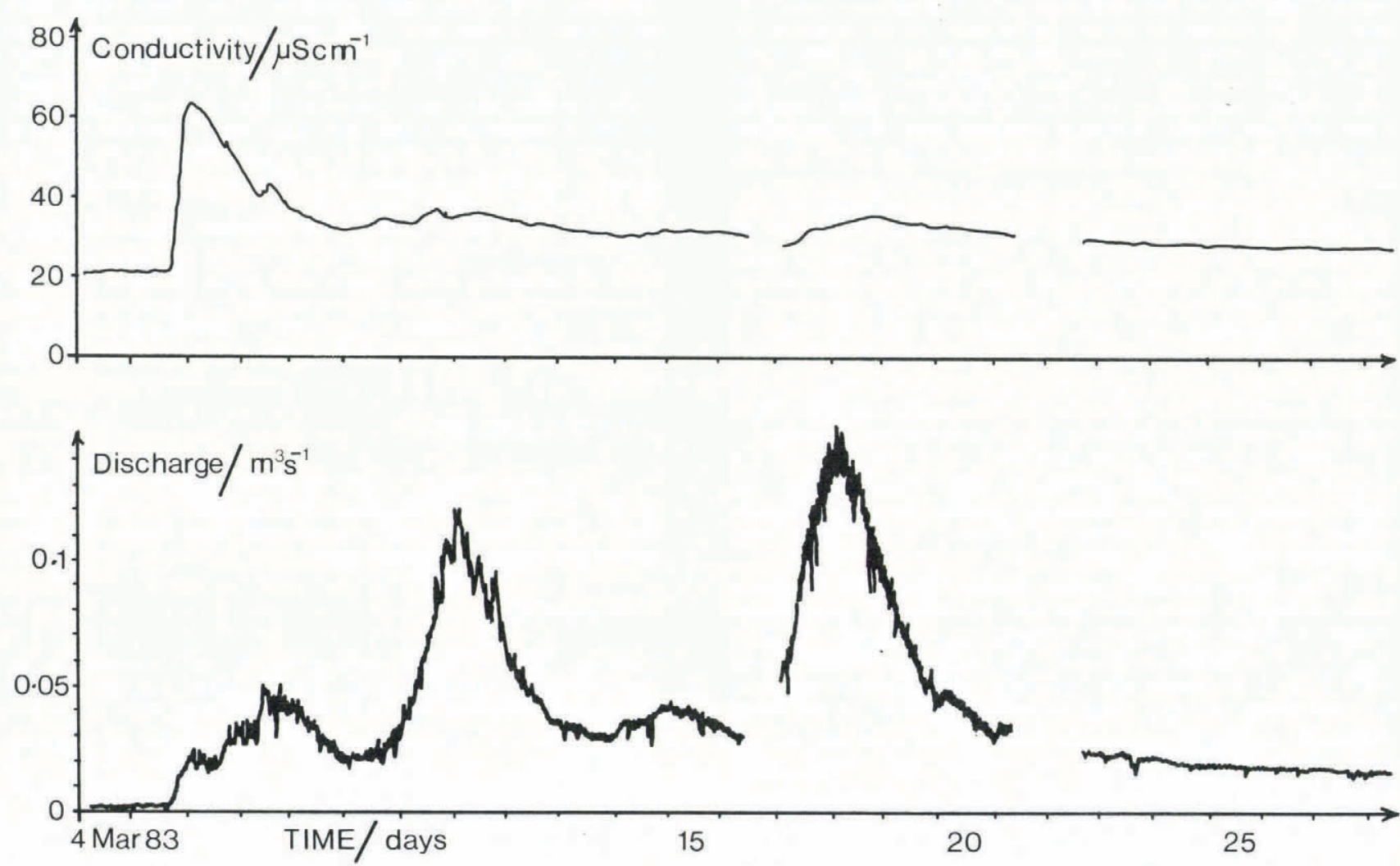

Fig. 1. Conductivity and discharge during the first major snowmelt event. 

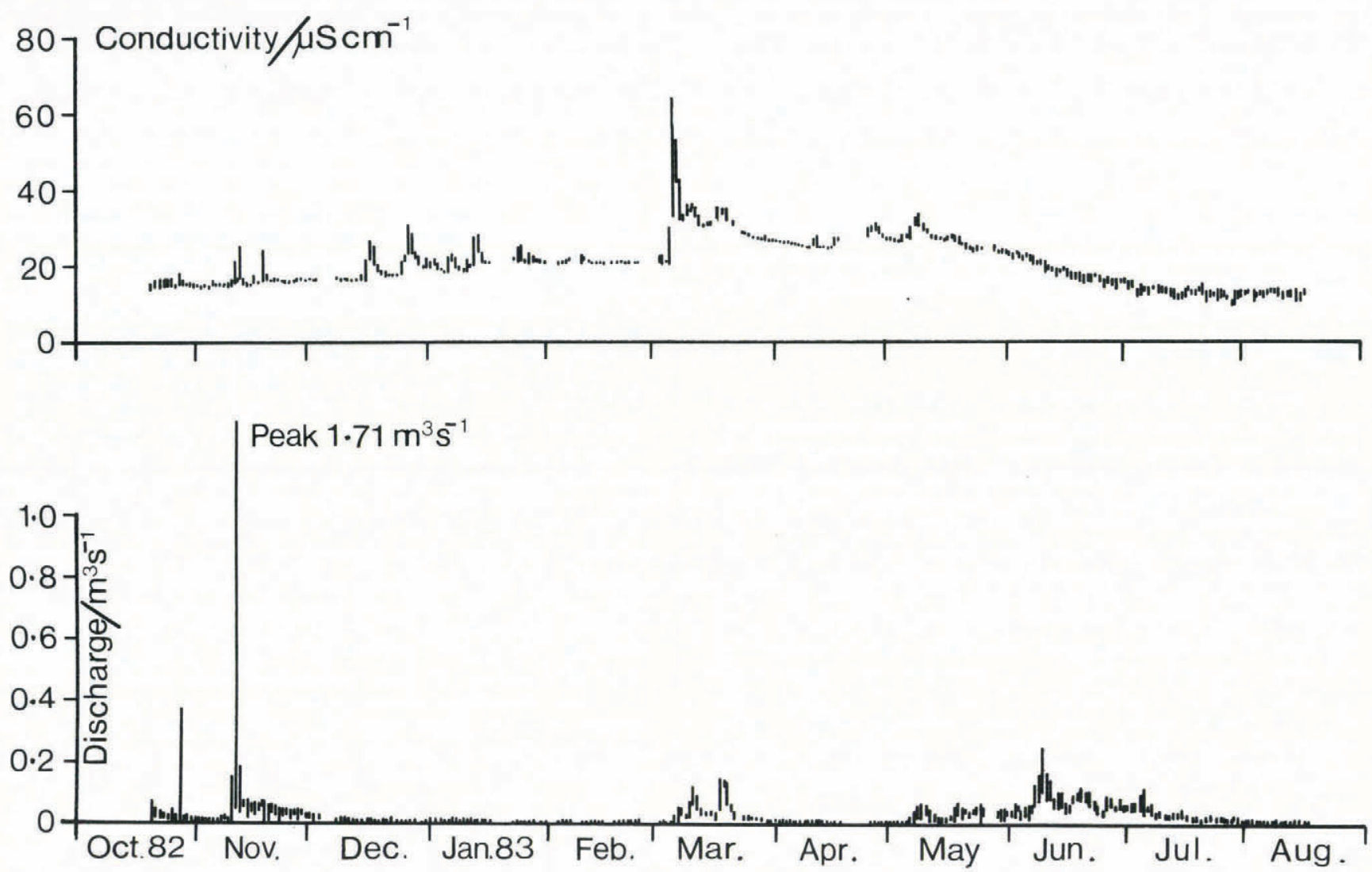

Fig. 2. Daily range of conductivity and discharge from October 1982 to August 1983.

water had a maximum concentration factor towards the upper end of this range. The wide variation in the maximum concentration factor in the laboratory experiments may be attributed (i) to variation in the vertical distribution of the impurities in the snow with a higher factor occurring if the impurities are concentrated near the base of the column (Colbeck, 1981), and (ii) to variation in the type of impurities, since not all ions are leached from snow at the same rate. A high concentration factor in the first spring melt water in Ciste Mhearad is quite possible since previous minor snowmelt episodes may have produced a higher concentration of impurities at the base of the snow-pack.

Figure 2 shows the conductivity and discharge of the stream for the whole of the 10 month period. The range of the variables during each day is shown as a vertical line. There is a slow increase in the base level of conductivity during the autumn and winter when the discharge is very low and sustained by slow drainage of the soil and a decrease from March onwards when the streamflow is much larger and is fed by melt water from leached snow. Small peaks are associated with autumn rain storms in November and minor snowmelt events during December and January.

There is a small peak associated with the start of the second major snowmelt period in early May. Clearly the peak during the first snowmelt period in early March, which is shown in detail in Figure 1 , is the most significant event in the year.

The minor snowmelt peaks during the winter illustrate how pollutants may be released in several unimportant surges in British conditions. Although $c_{\text {av }} \approx \bar{c}$ and the ratio $c_{\max } / c_{3}$ is probably quite high, the discharge record shows that $f_{1} / f_{3}<1$. Hence the maximum concentration factor $n$ is only about 1.5 for these peaks. The effect of the slow snowmelt component $f_{2}$ can be seen in the slow rise in the base level of conductivity $c_{3}$ as the soil water gains pollutants from the snow.

The minor peaks in May illustrate the effect of snowmelt when $c_{\text {av }}$ is low and $c_{3}$ high. Here the discharge record shows $f_{1} \gg f_{3}$ but the ratio $c_{\max } / c_{3}$ is too small for a large peak to be produced despite the fact that preferential elution still occurs. A high snowmelt discharge in June produces no peak at all in conductivity so by this time $c \approx c_{3}$.

For most of the year conditions in Ciste Mhearad may be taken as representative of those in areas of similar altitudes, vegetation, and bedrock. The catchment faces south-east, so melt rates will be a little higher than those in north-facing areas. However, there is an unusually high rate of deposition of wind-blown snow in this catchment. Snow persists later into the year than in most other areas of the Cairngorms. Thus the data from October to May may be taken as applicable to other areas, whereas the summer snowmelt in June and July is a special aspect of the hydrology of Ciste Mhearad.

The field data from Ciste Mhearad show that even under British weather conditions a three-fold increase in the level of pollution in a stream can occur during snowmelt. We have explained why this may not happen in every year or in every upland catchment. Nevertheless, aquatic organisms are clearly at risk at the onset of snowmelt in Britain.

\section{ACKNOWLEDGEMENTS}

This paper appears with the permission of the Director of the Institute of Hydrology. We should like to thank $M$. Porter, S.J. Edwards, W.S. Insell, and R.J. Wyatt for their invaluable assistance in the field.

\section{REFERENCES}

Colbeck, S.C. 1981. A simulation of the enrichment of atmospheric pollutants in snow cover runoff. Water Resources Research, Vol, 17 No. 5, p. 1383-88.

Fowler, D., and others. 1982. Rainfall acidity in northern Britain, by D. Fowler, J.N. Cape, I.D. Leith, I.S. Paterson, J.W. Kinnaird, and I.A. Nicholson. Nature, Vol. 297, No. 5865, p. 383-86.

Johannessen, M., and Henriksen, A. 1978. Chemistry of snow meltwater: changes in concentration during melting. Water Resources Research, Vol. 14, No. 4, p. 615-19. 
Johannessen, M., and others. 1977. Acid precipitation in Norway: the regional distribution of contaminants in snow and the chemical concentration processes during snowmelt, by M. Johannessen, T. Dale, E.T. Gjessing, A. Henriksen, and R.F. Wright. [Union Géodésique et Géophysique Internationale. Association Internationale des Sciences Hydrologiques. Commission de Neiges et Glaces.] Symposium. Isotopes et impuretés dans les neiges et glaces. Actes du colloque de Grenoble, août/septembre 1975 , p. 116-20. (IAHS-AISH Publication No. 118.)
Johannessen, M., and others. 1980. Streamwater chemistry before, during and after snowmelt, by $M$. Johannessen, A. Skartveit, and R.F. Wright. (In Drabløs, D., and Tollan, A., ed. Ecological impact of acid precipitation. Proceedings of an international conference, Sandefjord, Norway, March 11-14, 1980. Oslo-Ås, SNSF Project, p. 224-25.)

Skartveit, A., and Gjessing, Y.T. 1979. Chemical budgets and chemical quality of snow and runoff during spring snowmelt. Nordic Hydrology, Vol. 10, Nos. 2-3, p. 141-54.

MS. received 28 March 1984 and in revised form 31 October 1984 